\title{
SOBRE 0 ENSINO DE LITERATURA BRASILEIRA E LUSÓFONAS NOS ESTADOS UNIDOS E FRANÇA: DEPOIMENTOS
}

Italo Moriconi

(UERJ)

Florencia Garramuño Universidad San Andres - Argentina

\author{
Participam (em ordem alfabética): \\ Jacqueline Penjon (Profa. Emérita Sorbonne Nouvelle) \\ Kenneth David Jackson (Yale University) \\ Lucia Sá (The University of Manchester) \\ Luiz Valente (Brown University) \\ Michel Riaudel (Lettres Sorbonne) \\ Pedro Meira Monteiro (Princeton University)
}

\section{Nos Estados Unidos e Inglaterra}

1) Como avalia a posição dos estudos de literatura brasileira nas universidades americanas tendo em vista: a) o panorama dos estudo lusófonos em geral, e o dos estudos hispânicos e latino-americanos; b) a situação do interesse por assuntos brasileiros em outras áreas, como cièncias sociais, antropologia, história, artes.

\section{[Kenneth David Jackson]}

A posição, dentro de departamentos de Espanhol e Português, ou de Romance Languages/Modern Languages, é secundária e dependente das outras línguas para apoio. Com a exceção da Brown, não há estudos lusófonos; os hispano-americanos têm em geral pouco interesse no Brasil e pouco a nenhum conhecimento de autores e obras. b) nas outras áreas, há algum interesse no Brasil como campo de pesquisa (saúde pública, meio ambiente, medicina, ciências sociais), com limites. Nos últimos 20 anos, observamos a chegada de acadêmicos brasileiros para ocupar os postos de literatura luso-brasileira nas nossas universidades, que antes 
convidavam professores visitantes, agora vitalícios (i.e. Pedro Meira em Princeton, Bruno Carvalho em Harvard, Victoria Saramago em Chicago, Leila Lehnen na Brown, Rodolfo Franconi na Dartmouth, Sonia Roncador no Texas e assim vai). São os novos brasilianistas brasileiros, que se fixaram aqui.

\section{[Luiz Valente]}

Embora pequeno, o campo de estudos de lusófonos é bastante dinâmico nos Estados Unidos. Por exemplo, os congressos da American Portuguese Studies Association (APSA), realizados de dois em dois anos, atraem cerca de duzentos professores e estudantes de pós-graduação. (Esse número inclui uns cinquenta participantes vindos da Europa e do Brasil.) Considero a qualidade das comunicações apresentadas nos congressos da APSA mais alta do que a média em outros congressos de que normalmente participo, e os debates são geralmente bastante intensos. Muitas das pessoas se conhecem (devido ao tamanho do campo), o que beneficia a interação entre os pesquisadores mais estabelecidos e facilita a incorporação de nossos estudantes de doutorado.

Os professores e estudantes da área também participam ativamente de congressos de outras associações, como a Brazilian Studies Association (BRASA), a Modern Language Association (MLA), a American Comparative Literature Association (ACLA) e a Latin American Studies Association (LASA), que abrem espaços para os estudos lusófonos. Comparados ao estudos hispânicos, os estudos lusófonos constituem, todavia, uma parcela bem menor dos estudos literários nos Estados Unidos. Mas poderíamos dizer que o que perdemos em quantidade, ganhamos em qualidade e dinamismo.

Noto também bastante dinamismo, tanto no que diz respeito a publicações quanto a participações em congressos, nos campos da história e das ciências sociais embora os números de pesquisadores que se dedicam ao mundo lusófono nessas áreas também seja relativamente pequeno.

$\mathrm{O}$ interesse pelo estudo da língua portuguesa cresceu bastante entre 1985 e meados da década de 2010 (uma média de 5\% a cada cinco anos), mas houve uma queda de interesse nos últimos anos. $\mathrm{O}$ interesse pelo estudo da língua portuguesa e do mundo lusófono em geral tende a subir ou descer de acordo com como os americanos percebem a importância do Brasil no cenário mundial. 
Em todos os casos, dentro dos estudos do mundo lusófono, o maior interesse é, sem dúvida, pelo Brasil, (talvez 70\%) seguido da África lusofóna (20\%) e de Portugal (10\%), nessa ordem.

\section{[Pedro Meira Monteiro]}

É difícil traçar um quadro geral, porque a força dos estudos sobre o Brasil depende do trabalho que é feito individual e coletivamente em cada universidade. No caso de Princeton, estamos fundando o Brazil LAB (https://brazillab.princeton.edu), que é o embrião de um centro de estudos brasileiros. Trata-se de um $h u b$ interdisciplinar onde literatura e artes vão desempenhar um papel importante. Em termos mais gerais, essa iniciativa vai além da geografia institucional dos "area studies", e procura retomar o interesse pela língua portuguesa que vinha diminuindo nos últimos anos em razão da crise econômica no Brasil. Além disso, a crise democrática, alinhada a outras crises semelhantes pelo mundo afora, torna o Brasil novamente um "laboratório" interessante. É nesse sentido que os estudos sobre o Brasil (para além da literatura e dos estudos culturais, englobando ciências sociais, história etc.) podem estar diante de uma nova onda de interesse, em razão de cruzamentos e comparações não exclusivamente "regionais", mas que contemplem também países emergentes de todas as áreas do globo. Não só os países da América Latina, em suma.

\section{[Lucia Sá]}

Ensinar literatura brasileira no exterior é se dedicar a um assunto 'exótico' e minoritário. Minha experiência nos Estados Unidos (até 2005) e mais recentemente na Grã-Bretanha, é que de forma geral a literatura brasileira está atrelada a programas de Estudos Luso-Brasileiros (que incluem o ensino de língua portuguesa), que por sua vez tendem a vir a reboque dos programas de Espanhol. Em muitos programas, a literatura brasileira é ensinada lado a lado com as literaturas do restante da América Latina, em cursos temáticos; ou, particularmente na Grã-Bretanha, com as Literatura Portuguesa e Africana de de fala portuguesa. Além disso, é muito frequente que tenhamos que ensinar literatura e cinema, ou literatura e música popular, história, etc. $\mathrm{O}$ ensino de literatura brasileira como um assunto em si, é raro, um privilégio de algumas universidades de elite, onde o número de alunos por curso não é importante. Para a maior parte dos programas, simplesmente não há alunos suficientes para se criar cursos exclusivos de literatura brasileira; ou no máximo, há a possibilidade 
de oferecer um curso só num programa de 3 ou 4 anos. Nos EUA há uma liberdade maior para o professor criar diferentes cursos temáticos a cada ano. Em Stanford (onde ensinei de 1999 a 2005), por exemplo, eu criei vários cursos temáticos, alguns só de literatura brasileira (por exemplo, Literatura e Raça, Literatura e Desigualdade Social), mas havia, na época, uma grande pressão para eu criar cursos comparativos, ou entre literatura brasileira e literatura hispano-americana (por exemplo, o curso Vida na Megalópolis: São Paulo e Cidade do México; ou Teorias Culturais Latino-Americanas), ou cursos que fossem além da da literatura, como 'Lendo a Floresta Amazônica', que incluia textos de viagem, cinema, textos antropológicos, etc. Na Grã-Bretanha, o programa é muito mais rígido: cursos novos têm que ser aprovados pela comissão de graduação da Faculdade, o que torna inviável variar os cursos a cada ano. $\mathrm{Eu}$ dou um curso de Literatura Brasileira no segundo ano, que abrange só 4 autores, todos canônicos: Machado, Graciliano, Clarice e Guimarães Rosa. Além disso, eu e meu colega de cultura portuguesa damos um curso de introdução aos estudos lusófonos, em inglês, que trata da questão da colonização e inclui alguns textos de literatura brasileira (Iracema, $\mathrm{O}$ Cortiço, o 'Manifesto Antropófago', além da 'Carta de Caminha' e alguns filmes). Para os alunos do último ano, eu dou um curso sobre a Amazônia que inclui cinema, literatura (inclusive narrativas indígenas), literatura de viagem, textos ligados a questões ambientais, etc. Tanto na Grã-Bretanha quanto nos Estados Unidos, é praticamente impossível criar um curso de literatura ou cultura brasileiras que não seja focado em questões sociais. Os alunos querem estudar e discutir questões raciais, a história do colonialismo, questões sociais, ambientais, etc.

Quantos às demais disciplinas, pelo que tenho visto tanto os programas de história como de antropologia têm aberto menos vagas dedicadas à América Latina, incluindo o Brasil. Na Grã-Bretanha, nos últimos anos o que se vê é uma tendência ao provincianismo, a se estudar só a Grã-Bretanha, e a um interesse cada vez menor pelo estudo de outros países, pelo menos na Antroplogia e na História, com exceção, talvez, do Oriente Médio e da China. Essa falta de interesse também tem afetado os programas de Línguas Modernas. O espanhol tem conseguido se segurar um pouco aqui na Grã-Bretanha (nos EUA, onde o espanhol é segunda língua, imagino que também continue forte), mas o francês, o italiano, o alemão, o russo, e o português têm sofrido bastante. Nos anos dourados do governo Lula, quando o Brasil parecia um país que finalmente ia dar 
certo, houve um grande aumento na procura por programas português e estudos brasileiros, mas a situação agora se inverteu.

2) Quais as mudanças mais significativas ocorridas nas últimas duas décadas nos estudos estrangeiros de literatura brasileira, em termos de ênfases temáticas e orientação crítica.

\section{[Kenneth David Jackson]}

A influência dos "cultural studies" que ocupou o lugar de estudos da história da literatura e leitura de "obras essenciais." A orientação mais influenciada pelos 'area studies' e temas sociais e históricos/ambientais. A eliminação quase completa de estudos linguísticos.

\section{[Luiz Valente]}

Há um grande interesse pela literatura produzida por mulheres ou que levanta questões de gênero e raça. Ultimamente tem aumentado também o interesse pela discussão da masculinidade e da temática "queer." Os chamados "estudos culturais" vêm perdendo a força nas últimas duas décadas.

Os pesquisadores dos estudos literários lusófonos tendem a ser mais abertos a novas tendências críticas do que os dos estudos hispânicos, geralmente mais conservadores.

\section{[Pedro Meira Monteiro]}

Como sugeri acima, o relativo esgotamento dos estudos de área, assim como a emergência de novas epistemologias e novos debates em torno do Sul Global, leva à melhor compreensão de fenômenos transnacionais, especialmente por conta de agendas políticas que põem em xeque formas tradicionais de representação e expressão mundo afora. Talvez estejamos num momento em que o jogo de escalas permite escapar com bastante força do âmbito regional. Compreender a "emergência" (como urgência, mas também como surgimento de novos atores) tem sido central para a compreensão do que ainda chamamos de literatura, especialmente no Brasil. Penso que este seja um viés importante do que se vem produzindo fora do Brasil, sobre a literatura e a cultura brasileiras. 


\section{[Lucia Sá]}

Creio que as maiores mudanças têm a ver com perda de prestígio da (ou de interesse pela) literatura. Como disse na resposta anterior, é difícil hoje a gente conseguir organizar um curso só de literatura: quase sempre temos que incluir cinema, música popular, política, história, etc para conseguir atrair alunos. Em termos de tendências críticas, tem havido uma grande ênfase em questões de gênero (incluindo teorias queer), questões raciais, e questões ambientais, incluindo-se a eco-crítica e os estudos sobre animais (animal studies).

3) Como avalia a presença de traduções de obras de literatura brasileira e sua repercussão nas últimas duas décadas (2000 a 2018), tanto em termos quantitativos quanto qualitativos, e comparativamente em relação a períodos anteriores? Destaca algum livro ou iniciativa?

\section{[Kenneth David Jackson]}

Há bastantes traduções, algumas boas, mas esgotam rapidamente. Dou curso sobre o romance brasileiro do século XX em tradução, para o qual não faltam títulos (muitos publicados na UK). A máxima novidade é a publicação dos contos da Clarice, num volume único acessível, e dos contos reunidos de Machado de Assis.

\section{[Luiz Valente]}

O número de traduções (inclusive re-traduções) tanto de autores contemporâneos quanto de autores canônicos, como Clarice Lispector, Guimarães Rosa, Euclides da Cunha e Machado de Assis, vem crescendo. Atualmente essas traduções são geralmente publicadas por editoras menores enquanto anteriormente eram publicadas por grandes editoras comerciais, como a Knopf. Circulam sobretudo no meio universitário e entre pessoas antenadas para a chamada "literatura mundial" ("world literature”). Há ótimos tradutores e a qualidade das traduções é alta.

\section{[Pedro Meira Monteiro]}

Os casos de Clarice e Machado são, ainda, bastante paradigmáticos. Clarice vem ganhando novas e importantes traduções, assim como Machado, mais recentemente. E tanto ela quanto ele obrigam editores e leitores a repensar a velha máxima segundo a qual o escritor brasileiro deve dar a entender o que é ser brasileiro, ou deve trazer o gosto do país 
para o público estrangeiro. O preconceito localista ainda existe e talvez nunca deixe de existir, mas Machado e Clarice são dois poderosos antídotos à ideia de uma literatura "representativa" do Brasil.

\section{[Lucia Sá]}

São poucas, muito poucas, as traduções de obras de literatura brasileira para o inglês, e a repercussão da nossa literatura nos países de fala inglesa continua a ser pequena. Uma das boas iniciativas tem sido o Programa de Apoio à Tradução e à Publicação de Autores Brasileiros no Exterior, da Biblioteca Nacional, mas muito mais poderia ser feito nessa área. Outra boa notícia dos últimos anos foi a publicação de traduções alternativas (e quase sempre melhores) da obra da Clarice e do Machado.

4) Como compara (se for possível uma visão "comprehensive") o grosso da produção bibliográfica americana com os tipos de produção correntes no Brasil nas duas últimas décadas? Existe um perfil científico geral que caracterize a produção crítico-histórica sobre literatura e cultura brasileira oriunda das universidades americanas?

\section{[Kenneth David Jackson]}

São na maioria estudos temáticos, concentrando-se numa obra específica, com bastante variedade. Têm um foco, de maneira geral, mais concentrado do que a produção brasileira, talvez pela influência da crítica literária, vinda da tradição de ensaios em inglês, e pelas exigências dos editores das poucas revistas abertas para estudos de literatura luso-brasileira. A revista mais importante, a Luso-Brazilian Review (Madison, Wisconsin) publica desde 1965. Assim, há apenas uns 50 anos de publicação no ramo.

\section{[Luiz Valente]}

Pergunta difícil de responder. O mundo acadêmico norteamericano é enorme (os EUA têm mais de 3.000 instituições de ensino superior) além de bastante pluralista. A competição para publicar livros nas melhores editoras universitárias ou artigos nas melhores revistas é intensa. Como é de se esperar, o volume de publicações sobre o Brasil é menor nos EUA que no próprio Brasil mas a qualidade é alta, devido ao rigor do processo de "peer review" num contexto altamente competitivo.

Se me permite um comentário adicional, parece-me que a pós-graduação em estudos literários vem crescendo de forma desordenada 
no Brasil, sem muita atenção à demanda por profissionais da área. Além disso teses e dissertações são às vezes imediatamente publicadas como livros sem passarem por um processo criterioso de revisão. Isso raramente acontece no mundo universitário norteamericano. Não é raro que os recém-doutores publiquem versões revistas e geralmente ampliadas de suas teses, mas a conversão das tese em livro geralmente leva de três a quatro anos (ou mais), e os editores exigem que os cacoetes que marcam as teses universitárias sejam eliminados na conversão para livro. Nesse sentido, a participação do "copy editor", uma verdadeira instituição nas editoras de maior prestígio, é essencial.

Sugiro que se dê uma olhada no artigo co-publicado por Marguerite Harrison, Leila Lehnen e por mim, que apareceu no número mais recente da revista Brasil: Brazil: A Journal of Brazilian Litrature. O artigo contém informações e avaliações importantes do panorama dos estudos lusófonos nos Estados Unidos (nas áreas de língua e literatura) que talvez sejam úteis para os leitores de Matraga. Aqui vai o link:

http://seer.ufrgs.br/brasilbrazil/article/view/84031

\section{[Pedro Meira Monteiro]}

Creio que cada vez mais a produção crítica que se faz fora do Brasil sobre o Brasil (não apenas nos Estados Unidos) seja parte integrante do panorama crítico brasileiro. Por exemplo, a categoria "brasilianista" era há pouco tempo vista ainda com uma desconfiança que vai aos poucos amainando (ela se torna cada menos uma categoria política, e cada vez mais uma categoria neutra, que apenas descreve aqueles que estudam o Brasil fora do país). O que se produz "fora", em suma, já está quase completamente integrado ao que se produz "dentro" do Brasil. Por exemplo, a grade conceitual que remete aos estudos pós-coloniais, ou mesmo à onda desconstrucionista dos anos 1990, ganha força e se canoniza mais rápido nas universidades americanas ao longo das duas últimas décadas, e em alguns casos o espaço de reflexão nessas universidades pôde servir de apoio a uma reflexão "brasileira" menos assombrada pelos marcos nacionais. Isso é bom, mas não creio que se possa dizer que é algo exclusivo da produção crítico-histórica produzida fora do Brasil. Talvez o "fora" e o "dentro" já sejam categorias bastante inúteis para se pensar a produção sobre a literatura e a cultura brasileiras. Princeton, Harvard, Brown, Berkeley, UCLA, Madison, etc já são "aqui”. 


\section{[Lucia Sá]}

Não sei se podemos chegar a conclusões genéricas a respeito da produção bibliográfica sobre literatura e cultura brasileiras na Grã-Bretanha e nos EUA em comparação com o Brasil. No Brasil a produção é maior e mais variada, porque a cultura brasileira ocupa, é claro, um lugar inevitavelmente muito mais central. É possível, por exemplo, enviar uma proposta para uma editora brasileira de um livro que trate de um autor só; já na Inglaterra ou Estados Unidos isso seria mais difícil, a menos que o autor fosse o Machado ou a Clarice. A tendência da produção sobre cultura brasileira nos Estados Unidos ou Grã Bretanha são os estudos comparativos com outros países; ou então os estudos mais abrangentes, temáticos, ou que possam ter uma repercussão para além do Brasil, como os estudos sobre questões raciais ou desigualdade social. Estou, no caso, falando de estudos publicados por editoras. Em termos de produção acadêmica, isto é, de teses de doutorado, uma vez mais a tendência são os estudos comparativos ou abrangentes. Uma proposta de tese sobre um único autor brasileiro dificilmente receberia financiamento aqui na Grã-Bretanha. Quanto a linhas teóricas ou tendências críticas, não vejo muitas diferenças entre o Brasil e os Estados Unidos ou a Grã-Bretanha, já que influência da academia anglo-saxã sobre o Brasil não só é grande como também é muito imediata.

\section{$\mathrm{Na}$ França}

1) Como avalia a posição dos estudos de literatura brasileira nas universidades francesas tendo em vista: a) o panorama dos estudos lusófonos em geral, e o dos estudos hispânicos e latino-americanos; b) a situação do interesse por assuntos brasileiros em outras áreas, como ciências sociais, antropologia, história, artes.

\section{[Jacqueline Penjon]}

Nas universidades francesas, os estudos de "língua, literatura e civilização estrangeira" disciplina português (estudantes que cursam a graduação) são concebidos em função da ideia de lusofonia. Isso significa que a literatura será dividida em três áreas: literatura portuguesa, brasileira e africana de expressão portuguesa. Em princípio, no $2^{\circ}$ ano de graduação o estudante tem uma apresentação geral da literatura brasileira e no terceiro ano o estudo de dois autores geralmente "clássicos" (por ex. Graciliano Ramos e Carlos Drummond de Andrade). No mestrado e no 
doutorado, o estudante pode se especializar em literatura brasileira mas no mestrado sempre terá que assistir a seminários também de literatura portuguesa ou africana de expressão portuguesa.

O interesse pelos assuntos brasileiros em áreas como história, (nível graduação) está crescendo, me parece. As universidades que perderam a "graduação em português" por falta de um número razoável de alunos, conseguiram obter o aval do ministério para "graduações mistas", por exemplo "graduação de história com "parcours" português, embora seja mais língua mas com pinceladas de literatura. Nos estudos hispânicos ou de qualquer outra língua, sempre é possível escolher na graduação uma matéria optativa que pode ser língua portuguesa ou literatura.

\section{[Michel Riaudel]}

Antes de mais nada, precisa entender o quadro francês. 1) O campo dos estudos de línguas estrangeiras estruturou-se em três ramos, em função dos concursos de contratação dos professores de $2^{\circ}$ grau: língua, literatura, civilização. A formação procura contemplar as três áreas, porém hoje a vertente linguística está em declínio no corpo docente, as vertentes literárias e civilizacionistas em concorrência, de um lado, com a literatura comparada, e de outro, com os historiadores e as ciências sociais. No caso do português, há hoje (no corpo docente, repito) uma predominância dos estudos literários (sendo o corpus de língua portuguesa pouquíssimo representado em nosso comparatismo), e uma sub-representação notável dos civilizacionistas (espaço abandonado às ciências sociais). 2) A segunda especificidade é a articulação de todos os ciclos, em particular o $2^{\circ}$ grau (collèges, lycées) e o ensino superior (graduação, mestrado, doutorado). Tradicionalmente a universidade forma os professores de colégios, liceus, garantindo também a reprodução do corpo docente acadêmico. A partir dos anos 70 (quando Portugal entra na União europeia, e o grupo português sendo então o mais numeroso entre as comunidades oriundas da imigração na França), constata-se uma expansão notável do português em todos os níveis. A abertura de concursos (para alimentar o $2^{\circ}$ grau: CAPES, Agrégation) oferece perspectivas profissionais aos estudantes; os departamentos (ou subdepartamentos) de português se multiplicam nas universidades, cresce também consequentemente o corpo docente, oferecendo formação específica desde a graduação até o doutorado. A partir dos anos 90, esse movimento se inverte e vão se perdendo cargos, se fechando graduações integralmente dedicadas ao português. 3) Quanto 
ao equilíbrio entre as áreas geográficas e nacionais do mundo lusófono, digamos que a partição Portugal/Brasil tende hoje mais ou menos a 50-50, reservando um pequeno espaço aos países africanos.

A conclusão é hoje uma posição que vai se fragilizando cada vez mais, declínio reforçado pelo recesso da procura pelos estudos literários em geral. Mantem-se um fluxo razoável de inscritos nas graduações voltadas para o mundo dos negócios (Langues étrangères appliquées), combinando 2 ou 3 línguas (onde a literatura não aparece). No campo institucional, o português faz parte da secção 14 (as disciplinas das línguas romanas) do Conseil National des Universités (CNU), junto com o espanhol e o italiano. Aproximadamente o português representa $10 \%$ desse campo românico, o espanhol 60\%, o italiano 30\% (sem fazer menção da língua romena).

\section{2) Quais as mudanças mais significativas ocorridas nas últimas} duas décadas nos estudos estrangeiros de literatura brasileira, em termos de ênfases temáticas e orientação crítica.

\section{[Jacqueline Penjon]}

No decorrer da última década, os concursos de recrutamento para professores do ensino secundário sofreram uma grande modificação. $\mathrm{O}$ CAPES não tem mais programa de literatura (a preparação ficava a cargo das universidades) e a Agrégation não foi aberta para o português desde 2015. Portanto cada professor tem toda liberdade para escolher os temas que quiser, às vezes influenciado pelos eventos culturais do ano. A literatura muito contemporânea, geralmente, só entra em seminários específicos de mestrado ou doutorado. Quanto à orientação crítica, não acho que houve mudança.

\section{[Michel Riaudel]}

A diminuição de vagas nos concursos, ou mesmo simplesmente a ausência de vagas, tem um efeito devastador: perda de atratividades dos cursos, falta de emulação entre alunos... A partir dos 70, a contratação nas universidades podia exigir (como em outras áreas de línguas estrangeiras) um currículo combinando agrégation (um concurso muito exigente) + doutorado. Hoje não se pode exigir dos raros colegas novos uma "agrégation".

A respeito da queda dos números de alunos nos estudos literários (todos os campos confundidos), me parece que estamos diante de um fe- 
nômeno mais profundo: o reino dos critérios econômicos e tecnocráticos desvalorizou aos poucos esse regime (literário) de conhecimento. Instalamo-nos em um modo de relação ao "real" terrivelmente redutor, uma lógica de empregabilidade a curto prazo, mas em sociedades em que o desemprego beira oficialmente os $10 \%$ da população ativa, pode-se entender a pressão para formações aparentemente mais "profissionalizantes".

Outra inflexão é a importância crescente dos cultural studies (gender, pós-coloniais, minorias...) e a valorização do (hiper)-contemporâneo. Isso implica a quase ausência da literatura colonial, e até certo ponto dos "clássicos", assim como um filtro social dominante que traz a tona novas questões ao mesmo tempo que corre o risco de substituir as complexas discussões sobre o "valor" literário por redutores "politicamente correto".

3) Como avalia a presença de traduções de obras de literatura brasileira e sua repercussão nas últimas duas décadas (2000 a 2018), tanto em termos quantitativos quanto qualitativos, e comparativamente em relação a períodos anteriores? Destaca algum livro ou iniciativa?

\section{[Jacqueline Penjon]}

Houve um aumento muito significativo das traduções de literatura brasileira fruto das estratégias desenvolvidas no âmbito das relações culturais França-Brasil. O Brasil foi convidado de honra do Salão do Livro em 1998 e 2015; 2005 foi o ano do Brasil na França, 2009 da França no Brasil ; em 1979 nasceu a editora A.M. Métailié que, para o mundo lusófono,

publica em duas coleções a literatura portuguesa e a literatura brasileira; em 2009, nascem as Editions Anacaona especializadas em literatura brasileira periférica ; do lado francês, o CNL (Centro nacional do Livro) ajuda os editores a financiar a tradução de algumas obras, lado brasileiro, as bolsas de tradução da Fundação Biblioteca nacional atuam da mesma maneira. As estatísticas disponíveis mostram que houve 157 livros brasileiros publicados na França entre 2005 e 2008. Para o Salão de 2015, nos anos 2015 e 2016, contei 45 traduções novas (literatura) publicadas entre todas as editoras (Gallimard, Actes Sud, Métailié, Chandeigne, Anacaona, etc.). A literatura brasileira começa a ser conhecida pelo grande público embora os temas de predileção desse público, nas mesas redondas do salão fossem sobretudo futebol e Amazônia. O exotismo continua atraindo, entretanto, Jorge Amado deixou de ser o escritor 
mais procurado. Seria muito subjetivo destacar um livro, mas acho que o trabalho da editora Métailié deve ser salientado, graças a ela, Machado de Assis é hoje reconhecido: todos os romances da segunda fase estão em edição de bolso: a "suíte machadiana".

\section{[Michel Riaudel]}

O dito "boom latino-americano" dos anos 60 na França foi na verdade um boom hispano-americano. $\mathrm{O}$ boom da literatura brasileira aconteceu aqui nos anos 80 . Beneficiou-se do movimento resumido no ponto 1, de uma crescente presença do Brasil na cena internacional (economia, diplomacia...), das sucessivas operações diplomático-culturais: anos França-Brasil (1986-1988), as "Belles étrangères" de 1987, o Brasil convidado de honra da Feira do livro de Paris em 1998 e 2015, o ano do Brasil na França (2005). Cada um desses eventos, por motivos diversos, estimulou as editoras a lançar traduções de livros brasileiros, em um mercado inflacionista (devido, entre outros fatores, a um dispositivo próprio ao comércio dos livros na França). Esse movimento positivo foi muitas vezes contrabalanceado pelo baixo número de vendas, dissuadindo as editoras de persistir com certos autores ou mesmo com a literatura brasileira em geral. Machado de Assis, Guimarães Rosa, Graciliano Ramos são ainda autores pouco conhecidos (Lispector sendo um caso a parte). Os canais de recepção (capazes de incentivar e promover a leitura dos autores brasileiros (ver ponto 1), e aconselhar editores a apostar em tal ou tal título) são limitados, o que freia essa circulação.

Me parece importante fazer com que os leitores franceses sejam capazes de identificar alguns nomes, algumas figuras de destaque capazes, depois, de agregar, junto com o público, novas levas de autores. O Prix Roger Caillois recentemente atribuído a Milton Hatoum vai nesse sentido. Acho que são poucos, hoje em dia, os franceses, no grande público, aptos a citar um, dois, três nomes de escritores brasileiros.

4) Como compara (se for possível) o grosso da produção bibliográfica francesa com os tipos de produção correntes no Brasil nas duas últimas décadas? Existe um perfil científico geral que caracterize a produção crítico-histórica sobre literatura e cultura brasileira oriunda das universidades francesas ou mesmo europeias? 


\section{[Jacqueline Penjon]}

Não acho que exista um perfil científico que caracterize a produção crítico-histórica sobre literatura e cultura brasileira. Os ensaios variam muito em função das linhas de pesquisa escolhidas nas diferentes universidades. Trabalhos sobre exílio, memória ou autoficção ainda estão na moda. Evidentemente todos os grandes teóricos sobre esses assuntos são convocados.

[Michel Riaudel - em email]

Já publiquei diversos estudos sobre a presença da literatura brasileira na França, em maior parte para um período anterior ao contemplado pela pesquisa da Matraga, indicados abaixo. Vale também indicar que a revista «Reflexos » (on line: http://revues.univ-tlse2.fr/reflexos/) está preparando um dossiê sobre o ensino do português no mundo. Em breve, espero ter reunido mais elementos sobre esse assunto na perspectiva da comemoração do centenário da presença do português na universidade francesa (1919-2019). : (a) Michel Riaudel (dir.), France-Brésil, catalogue bibliographique commenté du Brésil dans l'édition en langue française, Paris : Association pour la diffusion de la pensée française, 2005, 222 p. ; (b) Michel Riaudel et Pierre Rivas (dir.), « La littérature brésilienne », in Europe, n 919-920, Paris, novembre 2005, p. 3-306; (c) Michel Riaudel, « Teria havido um boom latino-americano ? », trad. Márcia Aguiar, in Sandra Reimão et Michel Riaudel (dir.), Livros, literatura \& história: Passagens Brasil-França, Florianópolis: Escritório do livro, 2017, p. 11-47; (d) Michel Riaudel, « Réflexions sur l'étude des transferts littéraires ", in Anaïs Fléchet et Marie-Françoise Lévy (dir.), Littératures et musiques dans la mondialisation, $X X^{e}-X X I^{e}$ siècles, Paris : Publications de la Sorbonne, 2015, p. 175-183.

Nota: Os editores agradecem a colaboração da Profa. Masé Lemos (UniRio). 